\title{
THE CEPHALOPOD PREY OF THE WEDDELL SEAL, LEPTONYCHOTES WEDDELLII, A BIOLOGICAL SAMPLER OF THE ANTARCTIC MARINE ECOSYSTEM.
}

Negri, A. ${ }^{1}$, Daneri, G. A. ${ }^{2}$, Ceia F. ${ }^{3}$; Vieira R. ${ }^{3}$; Cherel Y. ${ }^{4}$; Coria N.R. ${ }^{5}$; Corbalán A. ${ }^{6}$ \& J. C. Xavier 3,7

$1-$

2-

3- Institute of Marine Research (IMAR), University of Coimbra, Portugal

$4-$

$5-$

$6-$

7- British Antarctic Survey, NERC, Cambridge, UK

Climate change has an impact on both the physical and biological components of ecosystems, and global-climate models predict enhanced sensitivity in polar regions.(Proffit et al. 2007). Such context has raised concerns for Antarctic animal populations that may show direct responses to changes in sea-ice distribution and extent, sea surface temperature or indirect responses to changes in prey distribution and abundance (Proffit et al. 2007). In this regard, the investigations of the feeding habits of Weddell seals Leptonychotes weddellii are of considerable importance to understand the role they play as top predators within the food webs of the Antarctic marine ecosystem, especially considering that this area is one of the most affected by climate change. This phocid species has a circumpolar range and inhabits the fast ice areas of the Antarctic continent and adjacent islands (e.g. South Orkneys, South Shetlands, South Georgia) (Reeves et al. 1992). The unique hole-breathing behaviour of Weddell seals allows them to live under continuous sea-ice. Moreover, combined with the ability to dive to depths of 700 to $800 \mathrm{~m}$ (Castellini et al. 1992, Testa 1994), Weddell seals are the only air-breathing predators capable of foraging in both benthic and pelagic habitats throughout the ice-covered oceans over the Antarctic continental shelf (Lake et al. 2003). This feeding behaviour makes them one of the most important apex predators in the food webs of the Antarctic marine ecosystem and a potential environmental indicator of how the Southern Ocean is functioning.

In the last decades, top predators, such as seals, have been used as biological samplers in order to collect information on the poorly known, but ecologically important, cephalopod fauna of the Southern Ocean (Cherel et al. 2004). For example, cephalopod eaters catch larger specimens and a greater diversity of species than sampling gear (Rodhouse 1990). Moreover, the increasing knowledge on the morphology of cephalopod beaks (chitinous hard structures that resist digestion) has allowed the identification to the species level of most of the accumulated items found in predators' stomach (Clarke 
1986, Imber 1992, Xavier and Cherel 2009). In addition, an innovative tool has been developed to investigate the trophic structure of cephalopods by combining the use of their predators as biological samplers together with measurements of the stable isotopic signature of their beaks (hard structures that resist digestion) (Cherel and Hobson 2005). Combining these tecnhiques applied to beaks found in the diet of weddell seals, it can provide useful information about the composition, distribution, abundance and ecology of cephalopods occurring within weddell seals foraging range (Cherel and Hobson 2005).

To date, most dietary studies of Weddell seals, mainly based on scat or stomach content analysis, have indicated that fish, cephalopods and crustaceans are their dominant prey taxa: the relative contribution of each of these food items to the overall diet of seals is highly variable, both temporally and spatially (e.g. Dearborn 1965; Plötz 1986; Green and Burton 1987; Plötz et al. 1991; Castellini et al. 1992; Casaux et al. 1997; Burns et al. 1998; Lake et al. 2003; Zhao et al. 2004; Casaux et al 2009, Daneri et al. 2012). However, few studies have focused on the cephalopod portion of their diet in detail (Clarke and MacLeodd 1982, Daneri et al. 2012).

Thus the aims of the present study applied to weddell seals from Antarctic Peninsula were: 1) To examine in detail the composition of the cephalopod component of their diet by means of scat analysis; 2) To assess the habitat use and trophic level of the different cephalopod prey taxa identified, by measuring the stable isotopic signature of the cephalopod beaks found in their diet. From mid January to February 2009, a total of 48 faecal droppings were collected at Hope Bay (Lat, $63^{\circ} 24$ S; Long. $57^{\circ} 00$ W), Antarctic Peninsula, next to the Argentinian scientific station Esperanza, and kept frozen at $-20^{\circ} \mathrm{C}$. Once in the laboratory, these were sieved (mesh size $1 \mathrm{~mm}$.) through running water, and prey remains sorted under a binocular microscope. All the lower beaks were identified to the lowest possible taxonomical level using reference collections and appropriate guides (Lipinski and Woyciechowski 1981, Clarke 1986, Xavier and Cherel, 2009). Mantle length and mass of the different cephalopod species were estimated from the lower hood length of beaks, using previously published regression equations (Clarke 1986, Xavier and Cherel, 2009). Furthermore, subsamples of beaks were separated, cleaned and kept in $70 \%$ ethanol for further isotopic analysis. For each species, for each island, 10 random lower beaks in good condition, were selected following Cherel \& Hobson (2005). Prior to the analysis, the beaks were dried at $60^{\circ} \mathrm{C}$ and grinded into a fine powder; 0.30 to $0.55 \mathrm{mg}$ of each beak sample were placed in a tin capsule, and the stable isotope signatures were measured using a Flash EA 1112 Series elemental analyzer coupled on line via Finningan conflo II interface to a Thermo delta $V \mathrm{~S}$ mass spectrometer. The Carbon and Nitrogen isotope signatures were expressed in delta $(\delta)$ notation relative to PDB limestone for $\delta$ $13 \mathrm{C}$ and atmospheric Nitrogen (AIR) for $\delta 15 \mathrm{~N}$. 
The analysis of scats containing prey remains $(n=46)$ indicated that fish were the most frequent prey of seals occurring in $100 \%$ of samples, followed by cephalopods, which were present in $37 \%$ of scats. The occurrence of crustacean remains was negligible. A total of 83 cephalopod beaks (34 upper and 49 lower) were removed from scats. This prey taxon was represented only by octopods of the subfamily Eledoninae. The dominant prey species was Pareledone turqueti, which occurred in almost $70 \%$ of scats containing cephalopod remains, and represented over $40 \%$ in terms of numerical abundance and $60.5 \%$ in mass of cephalopods consumed. This species was followed by the 'Papillated Pareledone' species group and Adelieledone polymorpha (Table 1).

In relation to the papillated group, it is worth emphasizing that, until recently, all papillated specimens of Pareledone from the Antarctic Peninsula area were ascribed to the species $P$. charcoti. However, a reexamination of the papillated-type material of Pareledone, coupled with extensive fishing over several years off the Antarctic Peninsula, has led to the identification of at least eight new species of papillated Pareledone from the Antarctic Peninsula region (Allcock 2005; Allcock et al. 2007). These are distinguished by subtle taxonomic characters, such as the morphology and placement of their papillae, whereas traditional features, such as beak morphology, fail to separate them as they all show a strong resemblance to $P$. charcoti (Allcock 2005).

The $\delta^{13} \mathrm{C}$ and $\delta^{15} \mathrm{~N}$ (mean $\pm \mathrm{sd}$ ) values in beaks of these three octopodid taxa combined were $-18.9 \pm 1.1 \%$ and $7.1 \pm 0.6 \%$, respectively (Table 2). Based on the cephalopod prey identified from seal scats in this study, it is suggested that, during the summer season of 2009, Weddell seals preyed primarily on benthic prey resources. This finding coincided with the high abundance of benthic fish prey of the families Nototheniidae and Channichthyidae in the diet of seals during the above mentioned period, both families constituting over $78 \%$ in number and almost $90 \%$ in mass of the fish predated (Daneri and Negri unpublished data). From the $\delta^{13} \mathrm{C}$ and $\delta^{15} \mathrm{~N}$ values in beaks of the three octopod prey taxa identified, it was observed that these showed similar mean values (table 2). However, the Papillated Pareledone species group had a higher range and standard deviation, presumably due to the fact that it is precisely "a group" and thus, includes several octopod species. Notwithstanding, the relatively similarity in values would indicate that these three octopod prey taxa share the same type of habitat and occupy similar trophic level positions in waters close to the Antarctic Peninsula (Figure 1).

Monitoring the diet of $L$. weddelli for a longer period of time (preferentially a decade) at different seasons of the year and therefore, at different stages of its annual cycle, i.e. reproductive/moulting phase, will be essential to gain adequate knowledge of its trophodynamics and its ecological role as a top predator of the Antarctic marine ecosystem. Moreover, the stable isotopic signature of beaks accumulated in predators' stomachs may reveal new and/or 
unexpected trophic relationships and migration patterns among poorly known cephalopod species and families in the area of the Antarctic Peninsula.

Acknowledgements

This research is partly funded by the Foundation for Science and Tecnhology (Portugal), and within the Portuguese Polar Program PROPOLAR.

\section{References}

- Allcock AL (2005) On the confusion surrounding Pareledone charcoti (Joubin 1905) (Cephalopoda: Octopodidae): endemic radiation in the Southern Ocean. Zool J Linn Soc 143:75-108.

- Allcock AL, Strugnell JM, Prodöhl P, Piatkowski U, Vecchione M (2007) A new species of Pareledone (Cephalopoda: Octopodidae) from Antarctic Peninsula waters. Polar Biol 30:883-893.

- Burns J, Trumble S, Castellini M, Testa J (1998) The diet of the Weddell seals in McMurdo sound, Antarctica, as determined from scat collections and stable isotope analysis. Polar Biol 19:272-282.

- Casaux R, Baroni A, Carlini A (1997) The diet of the Weddell seal Leptonychotes weddellii at harmony point, South Shetland Islands. Polar Biol 18:371-375.

- Casaux R, Carlini A, Corbalán A, Bertolin L, DiPrinzio CY (2009) The diet of the Weddell seal Leptonychotes weddellii at Laurie Island, South Orkney Islands. Polar Biol 32:833-838.

- Castellini M, Davis R, Kooymann G (1992) Diving behavior and ecology of the Weddell seal: annual cycles. Bulletin of the Scripps Institution of Oceanography, vol 28. University of California Press.

- Cherel, Y., Duhamel, G. \& Gasco, N. (2004) Cephalopod fauna of subantarctic islands: new information from predators. Mar. Ecol. Prog. Ser. 266, 143-156.

- Cherel Y, Hobson K (2005) Stable isotopes, beaks and predators: a new tool to study the trophic ecology of cephalopods, including giant and colossal squids. Proc R Soc Lond B 272:1601-1607

- Clarke M, MacLeod N (1982) Cephalopod remains in the stomachs of eight weddell Seals. Br Antarc Surv Bull 57:33-40

- Clarke MR (1986) A handbook for the identiWcation of cephalopod beaks. Clarendon Press, Oxford.

- Daneri, G.A., Carlini; A.R., Negri, A., Allcock, L. and A. Corbalán. (2012) Predation on cephalopods by Weddell seals, Leptonychotes weddellii, at Hope Bay, Antarctic Peninsula. Polar Biology 35:585-592

- Dearborn J.1965. Food of Weddell Seals at Mc Murdo Sound, Antarctica. J Mammal 46:37-43. 
- Green K. and Burton H. 1987. Seasonal and geographical variation in the food of Weddell Seals Leptonychotes weddellii in Antarctica. Austral Wildl Res 14:475-489.

Imber MJ (1992) Cephalopods eaten by wandering albatrosses Diomedea exulans L. breeding at six circumpolar localities. Journal of the Royal Society of New Zealand 22: 243-263

- Lake S., Burton H. y Van den Hoff J. (2003). Regional, temporal and finescale spatial variation in Weddell seal diet at four coastal locations in east Antarctica. Mar Ecol Prog Ser 254: 293-305.

- Lipinski M, Woyciechowsky M 1981. Cephalopods in the food of Weddell seals from the Admiralty Bay (King George Island, South Shetland Islands). Pol Polar Res 2(3-4): 163-167.

- Plötz J (1986). Summer diet of Weddell seals (Leptonychotes weddelli) in the eastern and southern Weddell Sea, Antarctica. Polar Biol 6:97-102

- Plötz J., Ekau W., Reijnders P.J.H. (1991). Diet of Weddell seals Leptonychotes weddellii at Vestkapp, eastern Weddell sea (Antarctica), in relation to local food supply. Mar. Mamm. Sci. 7:136-144.

- Proffitt, K., Garrott, R., Rotella, J., Wheatley, K., 2007. Environmental and senescent related variations in Weddell seal body mass: implications for agespecific reproductive performance. Oikos 116, 1683-1690.

- Reeves RR, Stewart BS, Leatherwood S 1992 The Sierra Club handbook of seal and sirenians. Sierra Club Books. San Francisco.

- Rodhouse, P.G.K, Prince, P.A., Clarke, M.R. y A.W.A Murray. 1990. Cephalopod prey of the grey-headed albatross Diomedea chrysostoma. Marine Biology, 104: 353-362.

- Testa J.W. (1994). Over-winter movements and diving behavior of females Weddell seals (Leptonychotes weddellii) in the southwestern Ross Sea, Antarctica. Can. J. Zool. 72:1700-1710.

- Xavier JC, Cherel Y 2009. Cephalopod Beak Guide for The Southern Ocean. British Antarctic Survey, Cambridge, UK. 129pp.

- Zhao L, Castellini MA, Mau TL, Trumble SJ (2004) Trophic interactions of Antarctic seals as determined by stable isotope signatures.

Polar Biol 27:368-373 
Table 1: Taxonomic composition of the cephalopod prey of Weddell seals, Leptonychotes weddellii, at Hope Bay, expressed as the frequency of occurrence (f), percent frequency of occurrence (\%f), number of otoliths (n), percentage of the total number $(\% n)$, mass $(m)$ and percentage of total mass $(\% m)$.

\begin{tabular}{|l|l|l|l|l|l|l|}
\hline Species & $\mathrm{f}$ & $\% \mathrm{f}$ & $\mathrm{n}$ & $\% \mathrm{n}$ & $\mathrm{m}$ & $\% \mathrm{~m}$ \\
\hline Paraledone spp. & 6 & 50 & 19 & 38.8 & 1340 & 29.3 \\
\hline Pareledone turqueti & 8 & 66.7 & 21 & 42.9 & 2773 & 60.5 \\
\hline Adelieledone sp. & 5 & 41.7 & 9 & 18.4 & 468 & 10.2 \\
\hline
\end{tabular}

Table 2: Stable carbon and nitrogen isotope values of individual beaks of the three octopodid taxa prey of $L$. weddellii.

\begin{tabular}{|c|c|c|c|c|c|c|c|c|c|c|c|c|c|c|c|}
\hline Isotop & & & & & & \multicolumn{4}{|c|}{ Taxa } & & & & & & \\
\hline & \multicolumn{5}{|c|}{ A. polimorpha } & \multicolumn{5}{|c|}{ P. turqueti } & \multicolumn{5}{|c|}{ Pareledone spp ("Papilated") } \\
\hline & $\mathrm{n}$ & Mean & SD & $\min$. & $\max$ & $\mathrm{n}$ & Mean & SD & $\min$. & $\max$ & $\mathrm{n}$ & Mean & SD & min. & $\max$ \\
\hline d13C & 10 & $-18,8$ & 0,7 & -20 & $-17,6$ & 10 & $-19,1$ & 0,7 & -20 & $-17,9$ & 10 & -19 & 1,9 & -23 & -18 \\
\hline $\mathrm{d} 15 \mathrm{~N}$ & 10 & 7,3 & 0,4 & 6,8 & 8 & 10 & 7,7 & 0,7 & 6,8 & 8,8 & 10 & 6,3 & 0,5 & 5,5 & 7,3 \\
\hline
\end{tabular}


(a)

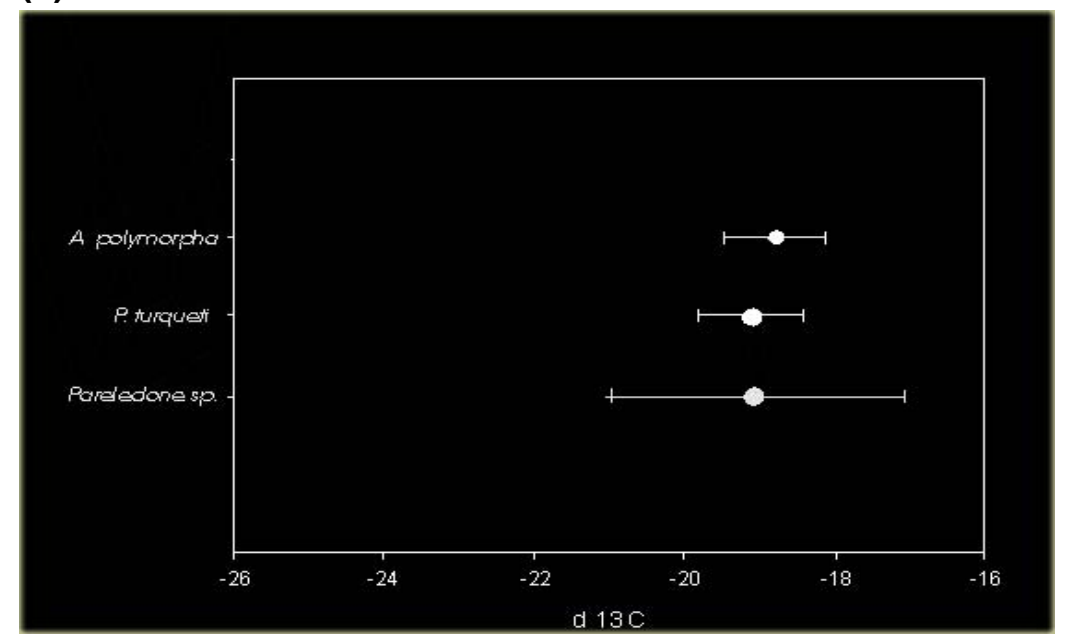

(b)

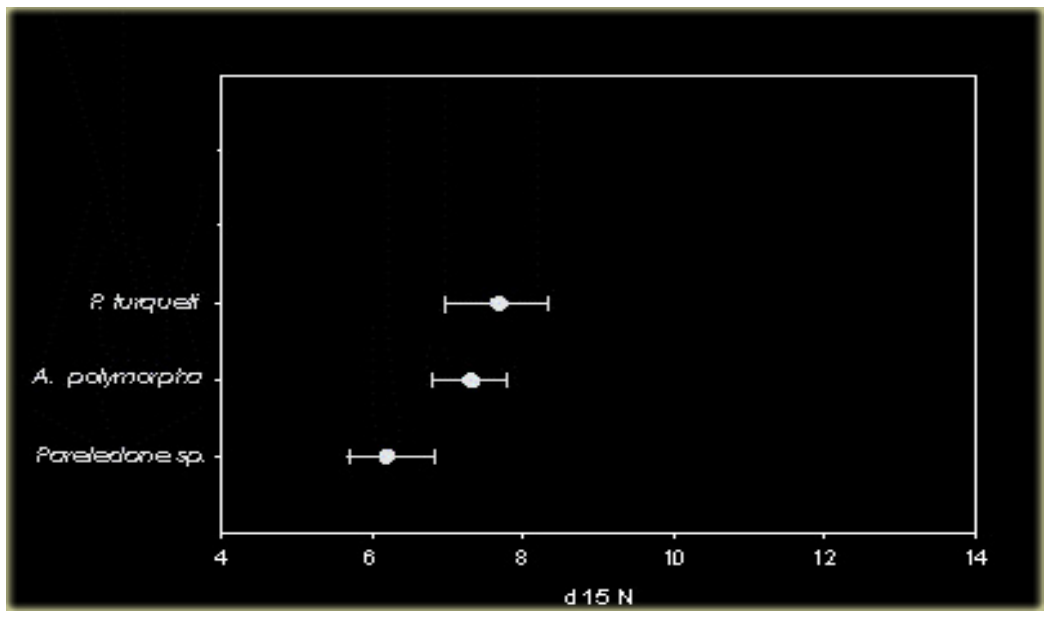

Figure 1: (a) Stable carbon and (b) nitrogen isotope values (Mean \pm SD) of beaks of the three octopodid prey taxa of $L$. weddellii. 